\title{
A Rare Case of Bilateral Primary B-Cell Non Hodgkin Lymphoma of Breast
}

Maharshi Romelbhai Raval ( $\triangle$ maharshiraval5897@gmail.com )

BJ Medical College https://orcid.org/0000-0002-3016-0078

Yash Patel

BJ Medical College

Suchi D. Shah

AMC MET Medical College Department of General Surgery

Kishan Gautam Patel

BJ Medical College

Kamal Sharma

UN Mehta Institute of Cardiology and Research Centre

\section{Research Article}

Keywords: Breast lymphoma, rare case, Bilateral Primary B-Cell, Non Hodgkin Lymphoma, PBL, SBL

Posted Date: July 7th, 2021

DOI: https://doi.org/10.21203/rs.3.rs-502417/v1

License: (c) (i) This work is licensed under a Creative Commons Attribution 4.0 International License. Read Full License

Version of Record: A version of this preprint was published at Journal of Surgical Case Reports and Images on July 19th, 2021. See the published version at https://doi.org/10.31579/2690-1897/080. 


\section{Abstract}

Primary B-Cell Non Hodgkin Lymphoma of Breast is a rare presentation of breast malignancy and it is necessary to differentiate it from secondary breast lymphoma as prognosis and treatment varies based on the diagnosis. We present a case of 47-year-old female with bilateral PBNHL of Breast which is rare due to younger age of presentation than earlier reported cases of this malignancy, lump with "peau de orange" appearance seen in both the breasts which is usually seen with high grade lymphoma and complete recovery of the patient while bilateral PBL outlines poor prognosis. Mammosonography findings included dilated ducts with hypoechoiec areas. MRI showed altered signal intensity. Findings of the imaging studies are non-specific and vary widely from case to case which is why biopsy which is gold standard was done to confirm the diagnosis.

\section{Learning Objectives:}

1. Recognize that diagnosis of PBNHL of Breast in relatively younger patient can be difficult even with mammosonography and MRI findings

2. Discuss the need of biopsy to identify the case of PBNHL of Breast

3. Discuss the treatment options

\section{Introduction:}

Breast lymphoma originates in the breast lymphoid tissue and includes primary breast lymphoma(PBL) which constitutes about $0.06 \%$ of breast malignancies, and secondary breast lymphoma(SBL) which constitutes about $0.12 \%$ of breast malignancies [1]. Wiseman and Liao outlines the diagnostic criteria for PBL which necessitates breast to be the primary clinical site without any prior history of extramammary lymphoma or widespread disease [2]. Scarce lymphoid tissue in the breast makes lymphoma a rare finding. Diagnosis is usually guided by radiological investigation following biopsy and FNAC. Biopsy sample should be investigated for histopathological examination and flow cytometry (specifically for ki 67 which is a replicative marker) [3].

\section{Case Presentation:}

A 47-year-old female patient, residing in Western part of rural India presented with chief complaints of lump in right breast involving all quadrants for 3 months. Lump was initially small in size and pain in thelump was present for last 1 month. Patient also noticed sudden increase in size of left breast for last 1 month which was associated with low grade fever and chills without rigor. There was no history of nipple discharge, trauma or insect bite. Patient visited private hospital and underwent truecut biopsy and was diagnosed to have granulomatous mastitis for which she took anti-tuberculous 4 drug treatment for 2 months. Local Examination of Right breast revealed redness and swelling over right breast, with peau de orange appearance and normal appearing nipple areola complex. Palpation showed raised local temperature and tenderness present in whole breast with diffuse lump of approximately $10 \times 10 \mathrm{~cm}$ sized 
involving whole breast with firm to hard consistency, fixed to the skin but not fixed to the chest wall. Left breast on inspection did not reveal any lump or redness or peau de orange appearance but on palpation approximately $5 \times 6 \times 2 \mathrm{~cm}$ sized lump was present in upper outer quadrant, well defined, firm to hard in consistency, mobile and not fixed to the skin and chest wall. Anterior axillary lymph nodes were palpable on both sides, multiple, firm to hard in consistency and freely mobile.

\section{Investigations:}

Her complete blood count reve4 Hemoglobin of $10 \mathrm{gm} / \mathrm{dl}$ with normal white cell and platelet counts.

Mammography revealed few prominent ducts present in upper outer quadrant. Pathological nodes in right axilla and metastatic lymph nodes in right supraclavicular and infraclavicular region, BIRADS II in right breast while left breast showed well defined soft tissue opacities in upper outer quadrant which on ultrasonography showed few dilated ducts with hypoechoeic area

True Cut Biopsy had revealed changes of chronic mastitis.

Breast MRI showed diffuse altered signal intensity noted in bilateral breast (Right > Left) with relative sparing of lower and outer quadrant of left breast. Right Breast was noted to be comparatively larger. Multiple enlarged heterogeneously enhancing lymph nodes were noted in bilateral axillary region (Level I and II), largest measuring approximately $33^{*} 16 \mathrm{~mm}$ on right side. Due to diagnostic uncertainty incisional biopsy on right side with excisional biopsy on left side was taken which showed bilateral breast involvement by follicular lymphoma with right axillary lymph nodes showing follicular lymphoma grade 2. Hematoxylin and eosin stained section of breast tissue showed sheets of pleomorphic cells with vesicular nucleoli resembling lyphoid cells thus clinching the diagnosis.

\section{Management:}

Currently, a combination of chemotherapy and radiation therapy are used, which was done in our case [4]. Patient was given three cycles of rituximab, cyclophosphamide, doxorubicin, vincristine, and prednisone (R-CHOP regimen) followed by Involved Field Radiation Therapy (IFRT). Similar to the treatment of breast carcinoma, lumpectomy with radiation therapy is often performed in patients with low grade breast lymphoma. Role of mastectomy in PBL is controversial, with many patients undergoing mastectomy due to diagnostic difficulty before the surgery, but its usefulness is similar to combination of chemotherapy and radiotherapy [5]. Prognosis is dependent on lymphoma type, grade and stage.SBL demonstrates a poor prognosis when compared with that of PBL and breast carcinoma.

\section{Discussion:}

This case represents very rare and unusual early presentation of breast neoplasm in form of bilateral Primary B-cell Non Hodgkin Lymphoma (PBNHL) of Breast, misdiagnosed initially as a granulomatous mastitis and finally required surgical biopsy which confirmed the diagnosis aided by immunohistochemical examination. Thomas et al. in a study of 1034 patients with PBL found the 
median age of presentation to be 66 years. Amongst the histopathologic subtypes, PBL is most likely to be a NHL(96.8\%). B-Cell lymphoma constitutes $92.5 \%$ and T-Cell lymphoma constitutes $3.7 \%$ of the NHL subtype. Predominant B-cell lymphoma is Diffuse Large B-Cell Lymphoma(39.6\%), followed by Marginal zone lymphoma(24.7\%) and follicular lymphoma(15.9\%). Anaplastic large cell lymphoma accounts for $2.4 \%$ of PBL with median age of diagnosis at 52 years [6]. In case of PBL, the common signs of symptoms of breast cancer such as skin retraction, erythema and peau d' orange are associated with high grade lymphoma or diffuse parenchymal involvement [7]. Bilateral breast involvement is a poor prognostic sign with increased risk of relapse and CNS involvement. Intrathecal CNS chemo-prophylaxis is advocated in a patient with bilateral DLBCL, but given the lack of data on CNS relapse, its usefulness is questionable [8-9]. Standardized protocol about management of patient recovered from bilateral PBL is needed.

\section{Follow up:}

Patient completed 1 month of follow up after three cycles of R-CHOP and involved field radiotherapy and there are no palpable masses on examination.

\section{Conclusion:}

We report a rare case of bilateral PBNHL of Breast in a young patient, diagnosed with biopsy and histopathological examination managed with combination of R-CHOP chemotherapy and Involved Field Radio Therapy. Imaging studies aids in diagnosis but due to its non-specific nature and provided that early diagnosis can prevent surgery and improve patient outcomes, biopsy with histopathological examination should not be delayed in patients with suspected breast lymphoma. Usefulness of CNS prophylaxis in a case of bilateral PBNHL of breast needs to be studied with clinical trials.

\section{Declarations:}

1. Funding: Not applicable

2. Conflicts of interest/Competing interests: On behalf of all authors, the corresponding author states that there is no conflict of interest.

3. Ethics approval: Not applicable

4. Consent to participate: Not applicable

5. Consent for publication: Consent obtained from the patient for publication of the case report

6. Availability of data and material: Not applicable

7. Code availability: Not applicable

8. Authors' contributions: Case report drafted by Dr. Maharshi Raval, found and followed up by Dr. Yash Patel, Dr. Suchi Shah and Dr. Kishan Patel. Dr. Kamal Sharma guided us through the process.

\section{References:}


1. Picasso R, Tagliafico A, Calabrese M, Martinoli C, Pistoia F, Rossi A, Zaottini F, Derchi L. Primary and Secondary Breast Lymphoma: Focus on Epidemiology and Imaging Features. Pathol Oncol Res. 2020 Jul;26(3):1483-1488. doi: 10.1007/s12253-019-00730-0. Epub 2019 Aug 20. PMID: 31428995.

2. Wiseman C, Liao KT. Primary lymphoma of the breast. Cancer. 1972 Jun;29(6):1705-12. doi: 10.1002/1097-0142(197206)29:6<1705::aid-cncr2820290640>3.0.co;2-i. PMID: 4555557.

3. Kreipe H. Ki67-Tumorheterogenität vs. Assayheterogenität [Ki67: biological intertumor variance versus variance of assay]. Pathologe. 2018 Dec;39(Suppl 2):272-277. German. doi: 10.1007/s00292018-0502-2. PMID: 30327857.

4. Caon J, Wai ES, Hart J, Alexander C, Truong PT, Sehn LH, Connors JM. Treatment and outcomes of primary breast lymphoma. Clin Breast Cancer. 2012 Dec;12(6):412-9. doi:

10.1016/j.clbc.2012.07.006. Epub 2012 Sep 25. PMID: 23018097.

5. Jennings WC, Baker RS, Murray SS, Howard CA, Parker DE, Peabody LF, Vice HM, Sheehan WW, Broughan TA. Primary breast lymphoma: the role of mastectomy and the importance of lymph node status. Ann Surg. 2007 May;245(5):784-9. doi: 10.1097/01.sla.0000254418.90192.59. PMID: 17457172; PMCID: PMC1877073.

6. Thomas A, Link BK, Altekruse S, Romitti PA, Schroeder MC. Primary Breast Lymphoma in the United States: 1975-2013. J Natl Cancer Inst. 2017 Jun 1;109(6):djw294. doi: 10.1093/jnci/djw294. PMID: 28376147; PMCID: PMC6059147.

7. Raj SD, Shurafa M, Shah Z, Raj KM, Fishman MDC, Dialani VM. Primary and Secondary Breast Lymphoma: Clinical, Pathologic, and Multimodality Imaging Review. Radiographics. 2019 MayJun;39(3):610-625. doi: 10.1148/rg.2019180097. Epub 2019 Mar 29. PMID: 30924754.

8. Ryan GF, Roos DR, Seymour JF. Primary non-Hodgkin's lymphoma of the breast: retrospective analysis of prognosis and patterns of failure in two Australian centers. Clin Lymphoma Myeloma. 2006 Jan;6(4):337-41. doi: 10.3816/CLM.2006.n.010. PMID: 16507213.

9. Hall KH, Valla K, Flowers CR, Cohen JB. Intrathecal Central Nervous System Prophylaxis in Patients With Diffuse Large B-cell Lymphoma at an Academic Healthcare System. Clin Lymphoma Myeloma Leuk. 2019 Feb;19(2):89-94. doi: 10.1016/j.clml.2018.11.014. Epub 2018 Nov 17. PMID: 30528416.

\section{Supplementary Files}

This is a list of supplementary files associated with this preprint. Click to download.

- image4.jpg

- whatsappimage20210425at5.jpg 